\title{
Group Work in EFL Children's Classes: A Qualitative Study
}

\author{
Reza Pishghadam \\ Ferdowsi University of Mashhad, Iran \\ Email: rpishghadam@yahoo.com \\ Mostafa Morady Moghaddam \\ Ferdowsi University of Mashhad, Iran \\ Email: mostafa_morady@yahoo.com
}

\begin{abstract}
This study aimed to investigate the place of group work among children in current EFL classes in order to examine the effect of group work on the language performance of children. This study consists of two phases; in the first phase, eighteen classes were observed to discover the place of group work and to find the quality of instruction. In the second phase of the study, the researchers conducted a class during a term (seventy one days) and focused on group work as the main tool for teaching to find out what would be the effects. When compared with the observed classes, the class which was taught in the second phase of the study, enjoyed considerable advantages, especially in memorizing conversations and learning new vocabularies. There was also little phonological and grammatical variation produced among children who learned the material through group work. In the end, some recommendations have been given.
\end{abstract}

Index Terms - group work, negotiation, output, responsibility, children, EFL class

\section{INTRODUCTION}

Before the advent of Roger's humanistic psychology (1980), the role of social and interactive nature of learning was to a large extent, and almost completely ignored. A glance at the history of SLA reveals that many researchers and authorities in their fervent effort have tried to find a decent theory of second language acquisition which would define language in its best and impeccable way. The effort, however, seems to make the waters muddier and as Kristeva (1989) rightly mentioned "that still unknown object"-language — is hard to define (p. 329).

This inquiry for finding the mind-boggling mystery of language acquisition in general and second language acquisition in particular, can be likened to a complex journey through a labyrinth in which models and theories one after another waned and waxed. In this process, new methods came into vogue with carrying with themselves some positive points of previous paradigms but expanding the field as bringing new perspectives. This is what Marckwardt (1972, p.5) called "changing winds and shifting sands" which represented the cyclical and diverse nature of paradigms. Sometimes a new theory found its way in the thriving history of second language which turned the pages of SLA history back to a couple of decades, and sometimes centuries ago. One case in point was the appearance of emergentism, a position which, according to Brown (2007), "oddly hearkens back to the spirit of behavioral approaches" (p. 32).

However, during the last two decades social learning theories have gained prominence. Through this framework, behavior is defined as the interaction between an individual and the environment (Taylor \& MacKenney, 2008). One of the leading proponents of social learning theories is Vygotsky who, according to Moll (1991), advocated that social relations and constraints make it possible for a child to reach higher psychological processes. Vygotsky (1978) further believed that learners have some potentiality that will be developed in interaction with others. It is also believed that the process of learning should be of integrative nature among students in which students are required to use their knowledge in the real world environment (Shokri, 2010).

Rogers's humanism and the works of Vygotsky were the pioneering efforts in order to bring students' interaction and group work to the forefront. Rogers's ideas informed teachers that they should provide a nurturing context for the learners so that they construct meaning through interaction with peers (Brown, 2007). Likewise, Vygotsky's theories emphasized the role of cooperative learning and advocated the idea of giving students more responsibility for their own learning (Taylor \& MacKenney, 2008). Vygotsky and Rogers, of course, are not the only ones who admired cooperative learning. The reputable Brazilian educator "Paolo Freire," in his everlasting masterpiece, Pedagogy of the Oppressed, vigorously objected to the dominant "banking models of education" and advocated "problem-posing education" in which he proposed that students should be free to cooperate with teachers and other learners in order to construct their own reality and reach the level of critical thinking (Freire, 1970). It has been claimed that group work among individuals can increase motivation considerably (Dörnyei, 2005).

A cooperative style of learning, as opposed to teacher-fronted methods, has gained importance and has been addressed by so many researchers as being one of the priorities in classrooms (Moutafidou \& Sivropoulou, 2010; 
Johnson, 2003). One of the components in Brown's ten principles of language learning/teaching is "to promote cooperative learning" (1994, pp. 189-215). He believed that cooperative learning plays down competition among students and provides the opportunity for students to share their knowledge. Kumaravadivelu (2003, p. 44) mentioned that one of the macrostrategies for language teaching is to "maximize learning opportunities." This strategy conveys this message that group work, as a powerful tool in the hands of the teacher, can be a good way in order to involve all the learners in the process of learning and, hence, there would surely be more opportunities for learning. Moreover, Kumaravadivelu emphasized on the notion of recognizing the learners' voice and define it as the 'learners' attempt to create learning opportunities for themselves and for other participants in class" (2003, p. 49).

More recently, the concept of output has gained popularity and some researchers across the world have tried to show its positive effects (Shehadeh, 2001; Swain, 2005). Group work can be a suitable activity in order to take output into consideration. When the learners work collaboratively and there is not an ever-present watchful eye above their heads, they will be more inclined to progress. It is believed that children will learn more when they are not watched or when they peripherally learn the language (Brown, 2007). One of the memorable sentences of Maria Montessori states that "The greatest sign of success for a teacher ... is to be able to say, "The children are now working as if I did not exist" (cited in Cummings, 2000, p. 2). This sentence carries a hidden message and that is the objection toward traditional approaches of teaching in which the teacher was the main source of knowledge and students were the passive receivers of information.

Students should be encouraged toward the active learning processes which Açıkgöz (2002) defined it as a process in which the learners take responsibility of their own learning and there are opportunities to take decisions. Teachers should be able to engage students in the process of learning in a way that they even forget there is such a thing as the teacher in the class. Students have the potential to lead the discussion, take responsibilities for what they are doing, and use their knowledge in order to communicate. This would help them to recognize what they are doing is practical and can bring about change to the environment - their friends. In his study, Bilen (2010) conducted a control group with a kind of passive instruction in which the teacher just explained and there was lots of questioning and answering among students and concluded that this prospect prevented teachers to use high level cognitive strategies in which knowledge is used within a broader situation.

All of these leading authors have recognized and advocated the role of group work in language learning. In this kind of procedure, students are not any more dependent on the authoritative role of the teacher and they try to learn from each other since they understand that they should rely on their own abilities (Williams \& Burden, 1997). In such cooperative activities, individuals are able to compare their development and performance to that of their peers and classmates. Teaching requires teachers to be more than a person transferring knowledge to students' minds. This obsession is rooted in the Krashen's input hypothesis in which he believed that "the only causative variable in second language acquisition is to provide comprehensible input" (Krashen, 1986, p. 61).

Having said that, in spite of all the attention that has been addressed toward interaction and negotiation, the role of cooperative learning in EFL classes among children is not obvious and there is not much at hand about the advantages of conducting group work among younger learners, especially children. Teachers can provide their students with bulky amount of learning opportunities if they precisely use cooperative activities in their classes. Since children are more engaged when playing or interacting with their peers, teaching children in groups can have better results. Most of the studies in the domain of group work deal with what learners learn during cooperative activities, however, in this article the way children deals with new information in group work is also considered.

\section{PURPOSE OF THE STUDY}

With the all attention that has been addressed toward cooperative nature of learning, little is known about the place of group work in English institutes among children and there is not much research available to show what and how would be the effects of group work. In this article the researchers tried to show the nature of some current teaching methodologies in the realm of children EFL education. The main concern of this study is to show the manifold advantages of group work among children in comparison to traditional ways of teaching which are not uncommon these days. This study is both descriptive and explanatory.

\section{METHOD}

\section{A. The First Phase of the Study (Observation of EFL Classes)}

For pinpointing the place of group work among children and its quality, eighteen English classes with different instructors were observed and audio-recorded. Ten institutes were chosen randomly from the city of Mashhad, Iran. The eighteen observed classes were from these ten institutes in a way that one or two teachers were selected in each institute to be observed. The aim of this observation was to recognize what would be the teachers' methodology toward presenting new information to children. In these classes the books were consisted mainly of "Let's Go" (3rd ed.) and "New Parade." These books are best-sellers. These eighteen EFL teachers were teaching in some other institutes all over the city of Mashhad and they were all considered as being experienced. Thus they might also present the same methodology in other institutes. Learners were mainly around 9. The total number of children in these classes was 180. 
In each day one class was observed. The time of observation for each session was around one hour. Each teacher was observed just for one session.

In these observations the researchers tried to figure out the relationship between children and the relationship between the teacher and children. The purpose of this phase of the study was to figure out the place and quality of group work in these classes, of course if there would be any. Furthermore, the way information was presented to children was investigated to reveal the quality of instruction. In every unit in these books there were some communicative activities. They are the parts that have the highest potential for presenting communicative activities (e.g., dialogues). The way these activities were presented by the instructor was carefully analyzed too.

\section{B. The Second Phase of the Study (Conducting a Cooperative Class)}

In the second phase of the study, the researchers ran an experiment with ten children who were approximately around ten and they were taught two days a week during a course of study (seventy five days). This course lasted sixteen sessions (each session took one and half an hour). The main concern was to present new information through implementing small groups for doing the activities in order to find out what would be the advantages in using cooperative activities. Does group work help children to deal with the conversations better or it is a waste of time? How about vocabulary learning? Do children learn new vocabularies better when they are working together? Do children learn from their partners' mistakes and whether they are able to correct them? Can it be a good way to bring fun and joy to the class by conducting group works? These and other similar questions are answered in this phase of the study.

\section{RESULTS}

The first phase of the study made it clear how various activities are dealt with in current EFL classrooms among children. For instance, the following are the results from two of the observations which revealed the following information.

\section{A. The Results of the First Phase of the Study}

\section{The first observation}

In one of the observed classes the teacher began the class by asking children to listen to the tape once. It was a short conversation between a girl and a boy. After the conversation finished, it seemed that children were to some extent confused. The teacher played back the tape and wanted students to repeat the dialogue after the tape and even names had to be memorized and pronounced perfectly. The dialogue was:

Hi, what's your name?

I'm Kate.

When repeating finished, children were asked to repeat the dialogue once again but this time the teacher herself was the model. After that, the teacher translated the meaning of the dialogue in Persian. She asked learners: "What's your name?" and some of the children answered "I'm Kate." In spite of the fact that children had repeated the dialogue for a couple of times, still there were some learners who could not manage the conversation correctly (sentences which are shown with an asterisk are wrong grammatically):

Teacher: what's your name?

* Student: I Ali.

The dialogue was played once more and children were asked to repeat after the tape. The learners who were not able to deal with the dialogue perfectly were reprimanded sharply by the teacher as being too slow or confused. Children finished repeating the dialogue but with some unpleasing experiences, since they were upbraided for not pronouncing the dialogue precisely. This destructive feature is seen in the discourse of some so-called teachers when interacting with children. Teachers in some of the classes that were observed, blamed children bitterly for not being able to learn and that they deserve failure since they could not pronounce the words perfectly. It was clear that children had not learned the dialogue precisely and most of them were confused. Moreover, the teacher just asked the children to answer. How about the question itself? That is, it was not clear whether children were able to manage asking for each other's names! They did not try asking each others' names.

It was time for "let's sing" part in which the dialogue was presented in a poetic way. After the learners listened to the tape, they were asked to tell the names of the children which were presented in the song! There were four names: Kate, Jenny, Scott, Andy. After the tape finished, children were asked to practice the pronunciation of the names not "how to ask for others' names." The teacher asked the learners, "Who wants to read the song?" but it seemed that nobody wanted to volunteer since the song was full of strange names and it was hard to pronounce them correctly. They even did not want to try. The learners who pronounced a name incorrectly were immediately stopped and asked to pronounce the names correctly. So much emphasis was placed on the correct pronunciation of exotic names that some of the students did not pay attention to other parts of the song at all and some of them seemed to just move their tongues purposelessly in order to match the sounds they heard.

However, in spite of a large amount of repetition, some of the children mispronounced the dialogue. For example, after so much repetition, there were some students who pronounced hi as hey. Even after recognizing the fact that children have not internalized the dialogue, the teacher continued to emphasize on precise pronunciation of words and 
exotic names. Little by little, a feeling of exhaustion was created in children. Again, some of the students, when they were asked, omitted the reduced form of am and said: "I Andy" instead of saying "I'm Andy." They were not deeply engaged in the process of communicating their names and instead tried to memorize how to pronounce those exotic words. They just recalled what they had repeated and the interfering effects of newly interred information influenced the loosely learned materials such as "I'm." This error-using "I Scott" instead of "I'm Scott"-was observed among some students and it seemed that no amount of repetition would help to correct this problem.

Then, it came to new vocabularies and the teacher followed the same procedure. She asked her students to repeat after her and she again took the lead. New vocabularies were taught using Persian translation. For instance, the teacher asked, "What does jump rope mean?" and she herself sooner than the others gave the Persian translation of that word. There was no elicitation to see whether they can apply what they have repeated to a new situation. Correct repetition of new words is not a good criterion for showing that students have learned the vocabularies. With the appearance of Ausubel's subsumption theory, the role of repetition was highly deemphasized since it was good only for short-term basis and was to a large extent mindless learning (1964). It seemed that pronunciation and Persian translation were the entire thing that mattered in this classroom.

It was vividly recognized that the main part of the lesson was dedicated to repetition of new items and Persian equivalents of those items without less or in some cases any application of that knowledge. Some students remained silent almost from beginning to the end. Participation on the part of the students was reduced to repetition of dialogues, vocabularies, and short sentences. This was the way children around the age of 10 were taught in one of the eighteen observed classes. The main textbook in this class was "Let's Go (let's begin)" student book.

The second observation

In another class that was observed, the teacher began by asking children to do the activities. First, she read the instruction which was about shopping in a mall and children were to give direction to a sport shop. There were some students who did not get the meaning of instruction and verbalized it to the instructor in their mother tongue. There were some who did not even find the page of the activity and they were searching for it. The teacher again read the instruction but this time at slower pace and with exaggerated pronunciation. The direction was: You are at the entrance of the mall. A boy stops you and says he wants to buy skates. Give him directions to Steve's Sport Shop. One of the children was absent last session and needed someone to review the previous lesson. To his surprise, the teacher said that 'there would be no reviewing.' If children were allowed to work with each other, the absentees might learn something from their friends. This also would allow the class to review what had been taught last session. Moreover, the class would have a chance to use what they had been taught purposefully.

There were various activities which required children to give address. However, they all reiterated the same direction for all the places. The teacher then explained the grammar part which was necessary for doing the next activity. She explained how to build comparative and superlative structures. She did not checked whether children had learned the grammar point. The teacher required one of the children to compare two objects which were written in their book. The student replied with considerable difficulty. This rightly showed that no amount of teacher explanation worked and the subsequent sentences from other students proved this. Moreover, children were not provided with feedback. Whenever a student made an error, another student was required to provide the correct answer, leaving the errors intact.

The next activity wanted students to give direction from their home to their school. One of the children said, "Go straight, and turn right, and turn left." As it was mentioned in the previous paragraph, students were just able to say limited sentences which were provided by the book-sentences such as go straight, turn left, and turn right. Again, in some similar activities, children were asked to use comparatives and superlatives. The following are sentences which were produced by some students:

* "The sneakers are comfortable than the skates"

* "The anklets are short than the knee socks"

* "The plaid socks are longest than the knee socks"

These errors were ignored by the instructor and it seemed that the children did not take any responsibility for what they were saying since there was nobody to give feedback to them. Children were corrected temporarily and so many errors passed unchecked.

Just as it was observed in the previous case, in this class the main focus was on reading aloud and perfect pronunciation since it was seen that trivial pronunciation errors which were considered as local errors were corrected immediately and outstanding errors such as the erroneous sentences which were mentioned above were ignored all together.

It was time for reading comprehension. The teacher required some of the children to read the passage aloud without any prior preparation or without activating their background knowledge. There were some pictures accompanied with the passage. The teacher could use them to activate student's schemata. Furthermore, she could ask students to practice it with a partner. Since the new words were not attended at all, it was not surprising that children one after another failed to pronounce the words and sentences correctly and the teacher, with an angry posture, stopped them while they were reading and corrected them. There were no paraphrasing and new vocabularies were taught by giving their Persian translation. There were some students who knew something about the meaning and the pronunciation of new vocabularies but the teacher did not use their knowledge and preferred to go through verbal gymnasium to explain the 
meaning of new words and did not allowed the students to participate. Some students were reticent all of the time and they just uttered something whenever they were asked.

In the book, there were a good deal of cooperative activities but the teacher insisted on her monologue. The entire thing that she did was to ask a couple of students to provide the answer. Although students had difficulty in providing the answers and there were some who answered incorrectly, there was not such a thing as feedback. Children were so eager to help each other; whenever one of them made a mistake or was not able to provide the answer, others tried to help him. In reading comprehension activities, one of the children made an error and another student figured out that but it was remained unnoticed from the eyes of the dominant teacher. This showed that students can take responsibility of their own as well as others' learning and can correct others if they will be given a chance to do so. Students are able to help each other and they should be allowed to do so. Unfortunately, the teacher stopped the students whenever a student had a mistake and either provided the answer herself or asked another student to give the correct response. There was an activity in the book its title was "think and discuss." The teacher, as it was the norm, took the lead and without giving students time to discuss the questions with a partner - the instruction wanted them to do so-asked the question from two of the students and the result was clear: some remained reticent and some were murmuring something in their mother tongue. For instance, one of the questions was: "What do you like to do on a trip (New Parade (5), p. 42)?" As it was mentioned above, students could not come up with a satisfactory answer. Maybe if they were allowed to share their ideas to a peer, some new ideas would trigger their minds.

In this class children were not provided with sufficient feedback and so many errors passed unattended. There were some children who preferred to remain silent and the quality of children's discourse was low in that they used their mother tongue much more than it was considered as being normal and it was mostly about the issues other than the subject matter.

\section{B. The Results of the Second Phase of the Study}

In the second phase of the study the researchers did an experiment to investigate what would be the effect of group work on children's performance. The performance of students was investigated and manipulated through sixteen sessions. Children were mostly ten. The researchers tried to break away from the common traditional ways of teaching that were observed in the institutes of foreign languages and observed classes - meaningless repetition and translation of items to the students' mother tongue. These two procedures were mostly, not to say completely, used in the classes the researchers observed. Thus, in this class a rather new way (in comparison to observed classes) of teaching was applied which was based on peer correction in which children were given responsibility for their own and others' learning.

The researchers wrote a short conversation on the board and read it once. It was worked with one of the children in order to make its meaning clear. Children were asked to memorize it without talking to their friends. Therefore, all the children were given time to memorize the dialogue - a process which was observed in some classes for the conversation part. After that, students were asked to come to the board and say the conversation by heart. The conversation is presented below:

A: Hello.

B: Hello.

A: How are you?

B: I'm fine thanks.

A: What's your name?

$\mathrm{B}$ : My name is ....

A: Nice too meet you.

B: Nice too meet you too.

It was recognized that children had some difficulty to overcome the fifth line which was: "What's your name?" Just two children out of ten were able to transcend the fifth line but they still had difficulty. The researchers assigned children to groups of two and wanted them to practice the dialog two by two without any memorization. They were said that they use their own names instead of memorizing exotic names. This gave the process a kind of real experience because they did not know each other's names exactly and they used this dialogue to find something-their friend's name.

It seemed that all of the children were engaged even though the researchers sometimes left the class to show them that they were teachers of themselves. In the middle of the activity, some children asked questions about the pronunciation of the words but the learners were not provided with the answer immediately. The researchers assigned a representative for each group and made him responsible to lead his group. Whenever there was a question, the leader was asked to help that student. Each group had a representative and the whole class had one or two main leaders. If the representative was not able to answer the questions, he was directed to the leader and if the leader was unable too, the researchers provided the answer just for the leaders and they had the responsibility to correct others. To the researchers' surprise, children were able to use and benefit from corrective feedback provided by representatives and the main leaders. Some children came up with different strategies in order to make the dialogue as comprehensible and manageable as possible. They even shared these strategies to other children especially when the size of the groups was large. 
It should be said that selecting a representative does not mean that others in the group should be silent. Teachers should inform representatives that every body in the group should talk and contribute equally. To create balance, after children have finished, teachers can first ask other students - not the representatives - to answer or participate. In every class there are some children who are more proficient. Teachers can use them in order to instruct weaker children. It works very well. For instance, if there is a weak student in the class, it will be a good strategy to ask one of those proficient students to work with him/her. It will have fascinating effects.

For checking whether students have learned well, two of the children were randomly asked to come to the board and this time they were progressing to a considerable degree. In following sessions some children were asked to come to the board and present the dialogue to see whether they have forgotten, as it was supposed to be so. However, children were able to present the dialogue even better than the previous sessions and this proved that if students really engage in an activity, they keep it longer since it is meaningful leaning. The researchers proposed that a group who all of its members would be able to conduct the conversation better and more fluently, will be given a positive mark. During the process, it was observed that nobody was silent and even those who were having problems learned from their eager representatives whose sense of ambitious was stimulated and wanted to prove their ability.

The researchers wanted to see whether group work can help students better learn new vocabularies. For doing so, eight adjectives were written on the board and their meaning was taught with showing pictures and giving examples. They were "new, old, pretty, ugly, happy, sad, hot, and cold." Children were asked to memorize the words without talking even a word to their friends. After five minutes, some students were asked to come to the board and say the adjectives. None of the children was able to give all the adjectives and their meanings. Then, the researchers required the children to practice the eight adjectives with a peer. After four minutes, students came to the board once more and presented the adjectives. This time six out of ten children were able to mention all the adjectives as well as their meanings. They were able to do so without any repetition or translation on the part of the teacher. They used their peer feedback and their strategies to pass the barriers even without the presence of the teacher-the researcher left the class periodically to see whether students would stop talking or they continue, which the latter came to be true. They were so eager that they did not pay attention to the passage of time. This process was repeated for other vocabularies in different sessions and almost the same result obtained.

Through these sixteen sessions, many conversations were presented to children and it seemed they can handle conversations better when they practice them in groups of two or four. To gauge how much they can improve, children were not assigned to groups from the beginning. They were first asked to memorize it without any help and without talking to their friends - a traditional way of learning which was observed in some classes. Their performance was recorded. After that, they were assigned to groups and their performance was recorded again. With comparing the first way of learning and the second method of working on conversations, it became clear how much they had improved or declined, which the results proved the former. It should be mentioned that the study was not reduced to working on conversations. Alphabets and words were also practiced in groups and the improvement was considerable as the results showed above. Group work was used to teach "members of the body," "colors," and "numbers." The results held true for these parts too. For instance, one of the students had difficulty to learn "eye." It was observed that his friend came up with a good strategy to teach him the word:

$$
\begin{aligned}
& \text { "The word eye is easy to learn; it is pronounced like 'I'- he wrote it down on his friend's notebook. If you forgot the word, } \\
& \text { just remember that it is pronounced like 'I'." }
\end{aligned}
$$

There were some children who invented a poetic way of learning vocabularies:

$$
\text { B b b bus, what is this? This is a bus. } \mathrm{d} \mathrm{d} \mathrm{d} \mathrm{dog,} \mathrm{what} \mathrm{is} \mathrm{this?} \mathrm{This} \mathrm{is} \mathrm{a} \mathrm{dog.}
$$

It should be mentioned that it was their first English class and they had not practiced English before but their minds were so prepared and creative.

\section{DISCUSSION}

When comparing the classes that were observed and the class which was taught by the researchers (every session just one researcher taught in the class), some interesting points became clear. The learning of new materials was more meaningful for the children who worked with groups. Sometimes after 4 or 5 sessions, children were able to recall information in spite of the fact that the researchers had not repeated them even once. The results of this study revealed that if children are assigned to group works, they will be able to learn better and longer. Furthermore, new vocabularies can be learned through the process of negotiation. It was observed that in most English classes the main approach toward teaching vocabulary is to give their Persian translation. The findings of this research showed that children will learn more vocabularies and they will keep it in their minds longer if they learn words in groups.

When the class is conducted in group work, all children's voices can be heard and this will give them a sense of achievement. They feel that they have been seen and they have been considered as a person who can contribute to the success of another student. This will intrinsically motivate them to improve since the better they learn, the better they can help their peers. In one of the sessions, in the second phase of the study, it was observed that one of the children 
was trying eagerly to learn the dialogue. The researcher approached him and asked about his motives. The student mentioned that he is trying hard in order to be able to help his friend which was much slower. This is because they want to show their capability to other children. Now there is something to fight for. When they are working with friends, they try more and they feel secure because they are not alone any more. Students who need more help use their friends' knowledge and those who are more proficient try to help others and through this, they will internalize what they have learned. Thus, group work is mutually beneficial for both partners.

At the end of these sixteen sessions, children were asked to give their opinions about group work. The following are some of their remarks:

- "When we think alone, it is hard for us to find the answer. Group work helps us to find the precise answer."

- "We can ask each other the things that we do not know. Group work is a place where asking and answering is a lot."

- "In group works we can make friends and we care for each other."

- "In groups we can finish activities sooner and our knowledge increases."

The following are some excuses for not using cooperative activities and group work in the class extracted from interviews with teachers:

- Methodology factors: The approach towards teaching does not allow using group work

- Student-related factors: Students are of different background knowledge and social status

- Management factors: The whole class may turn to a mess

- Feasibility factors: The environment and the facilities are not suitable

- Implementing factors: It is hard to implement group-work activities

- Assessment factors: It is hard to assess students properly

In general, teachers' unwillingness toward using group work among children can be shown in the following pie chart:

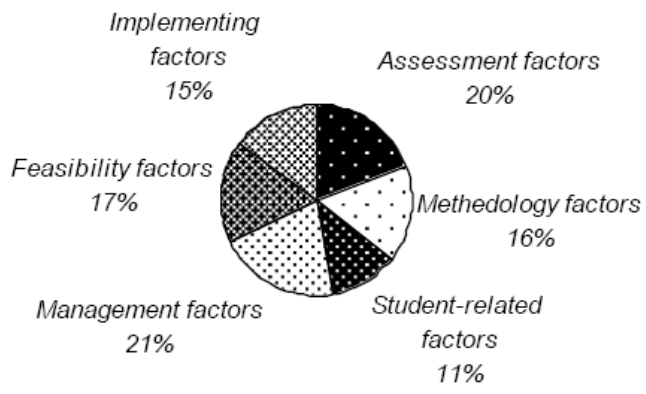

\section{CONCLUSION}

The main purpose of this study was to figure out whether group work can help children improve their performance. In order to find the answer, eighteen EFL classes were observed to find out the problems children would encounter in the classes and to consider the teacher's reaction against these problems. It was seen in these classes that teachers mainly resorted to rote repetition and Persian translation to teach the learners. Using these two processes exclusively created some problems in that children were not able to apply what they have rotely learned to a new situation and also they could not precisely recall what they have repeated. Since the auditory memory is highly limited, students were not able to recall the mimicked information. Meaning and long-term learning were not accounted for in observed classes.

One of the main advantages of group work is the enhancement of individual accountability. When children were divided into groups, they took responsibility for their own and their friends' learning. They figured out that the teacher is not like a television screen that they should watch without saying anything. In comparison to those eighteen classes, the class that was conducted in group work, helped children to increase their performance to a considerable degree, especially in vocabulary leaning and memorizing conversations for a longer time. In group works, children can jot down information to their friends and this would help them to make it more meaningful since they have transferred information and retell it in their own words. It should be mentioned that the teacher should be aware of quality and quantity of students' talk. Students should use the target language most of the time and they should also talk about the points which are wanted to accomplish not about something else. The advantages are not reduced to linguistic elements; as Brown (2001) put, group work increases students motivation and they feel a sense of security. Therefore, group work works to the benefit of both cognitive and affective domains of the learners.

Having said that, group work is not easy to conduct and it requires facilities and control. There were some institutes in which their classes were not spacious enough to conduct group work. There were some children who tried to dominate the conversation. Some teachers, when they were interviewed by the researchers, mentioned that there were some children in their classes who argue a lot and they cannot work with others easily. It requires teachers to have some good strategies to deal with these situations. On the whole, group work can bring a lot of fun and diversity to the class. 
This and so many other similar studies have tried to show the valuable effects of group work. However, one should not forget that group work requires skill and precision. If group work is not conducted carefully, the whole class will get out of control. Therefore, it should be under the supervision of the teacher. The Achilles heel of many cooperative activities is that students may deviate from the lesson. To avoid this pitfall, and other unwanted happenings, teachers should try to make group work as purposeful as possible. At the end, it should be mentioned that not the whole time of the class should be dedicated to group work because it will lose its effectiveness. With all its advantages and disadvantages, group work is a precious instrument which can bring variety and fun to the class.

\section{REFERENCES}

[1] Açıkgöz, K. Ü. (2002). Aktiföğrenme. İzmir: Eğitim Dünyası Yayınları.

[2] Ausubel, D. (1964). Adults vs. children in second language learning: Psychological considerations. Modern Language Journal, $48,420-424$.

[3] Bilen, S. (2010). The effect of cooperative learning on the ability of prospect of music teachers to apply Orff-Schulwek activities. Procedia Social and Behavioral Sciences, 2, 4872-4877.

[4] Brown, H. D. (1994). Teaching by principles: An interactive approach to language pedagogy. Englewood Cliffs, NJ: Prentice Hall Regents.

[5] Brown, H. D. (2001). Teaching by principles: An interactive approach to language pedagogy. Englewood Cliffs, NJ: Prentice Hall Regents ( $2^{\text {nd }}$ ed.). White Plains, NY: Longman.

[6] Brown, H. D. (2007). Principles of language learning and teaching ( $5^{\text {th }}$ ed.). White Plains, NY: Longman.

[7] Chomsky, N. (1965). Aspects of the theory of syntax. Cambridge: MIT Press.

[8] Cummings, C. (2000). Winning strategies for classroom management. Association for Supervision and Curriculum Development.

[9] Dörnyei, Z. (2005). The psychology of the language learner: Individual differences in second language acquisition. Mahwah, NJ: Lawrence Erlbaum Associates.

[10] Freire, P. (1970). Pedagogy of the oppressed. New York: Seabury Press.

[11] Herrera, M., \& Zanatta, T. (2001). New parade (5). Pearson Education: Longman.

[12] Johnson, B. (2003). Teacher cooperation: Good for some, not so good for others. Educational Studies, 29(4), 337-350.

[13] Krashen, S. (1986). Bilingual education and second language acquisition theory. In Sacramento, CA: California State Department of Education.

[14] Kristeva, J. (1989). Language the unknown. New York: Columbia University Press.

[15] Kumaravadivelu, B. (2003). Beyond methods: Macrostategies for language teaching. New Haven, CT: Yale University Press.

[16] Marckwardt, A. (1972). Changing winds and shifting sands. MST English Quarterly, 21, 3-11.

[17] Moll, I. (1991). The material and the social in Vygotsky's theory of cognitive development. Clearinghouse on teacher education. (ERIC No. ED352186).

[18] Moutafidou, A., \& Sivropoulou, I. (2010). Cooperation in all-day kindergarten teachers' beliefs. Procedia Social and Behavioral Sciences, 5, 350-355.

[19] Nakata, R., Frazier, K., Hoskins, B., \& Graham, C. (2007). Let's go: Let's begin ( $3^{\text {rd }}$ ed.). Oxford University Press.

[20] Rodgers, C. (1980). A way of being. Boston: Houghton Mifflin.

[21] Shehadeh, A. (2001). Self- and other-initiated modified output during task-based instruction. TESOL Quarterly, 35, $744-747$.

[22] Shokri, N. M. (2010). Team project facilitates language learning. Procedia Social and Behavioral Sciences, 7, 555-564.

[23] Swain, M. (2005). The output hypotheses: theory and research. In E. Hinkel (Ed.), Handbook of research in second language teaching and learning (pp. 471-483). Mahwah, NJ: Lawrence Erlbaum Associates.

[24] Taylor, G. R., \& MacKenney, L. (2008). Improving human learning in the classroom: Theories and teaching practices. NY: Rowman \& Littlefield Education.

[25] Ur, P. (1996). A course in language teaching: practice and theory. Cambridge: Cambridge University Press.

[26] Vygotsky, L. (1978). Mind and society: The development of higher psychological processes. Cambridge, MA: Harvard University Press.

[27] Williams, M., \& Burden, R. (1997). Psychology for language teachers: A social constructivist approach. Cambridge University Press.

Reza Pishghadam is associate professor in TEFL at Ferdowsi University of Mashhad. His major research interests are: Psychology and Sociology of language education.

Mostafa Morady Moghaddam is an M.A. student in TEFL studying at Ferdowsi University of Mashhad, Iran. He got his B.A in TEFL at Islamic Azad University of Mashhad, Iran. 